\title{
O ESTADO DA ARTE DA GESTÃo PÚBLICA
}

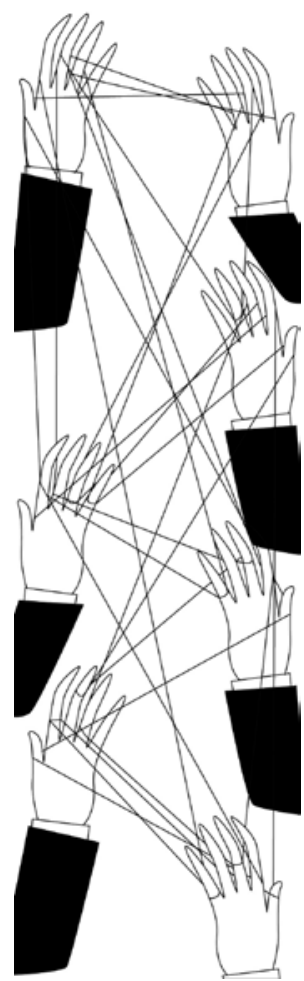

Paulo Roberto de Mendonça Motta paulo.motta@fgv.br

Professor da Escola Brasileira de Administração Pública e de Empresas, Fundação Getulio Vargas - Rio de Janeiro - RJ, Brasil

\section{INTRODUÇÃO}

A perspectiva contemporânea sobre o estado da arte na Administração Pública revela não só uma recorrência de temas, dilemas e paradoxos mas também uma constante busca de relevância e de novos conhecimentos para a solução de problemas práticos. O olhar histórico facilita a compreensão da validade e a relevância do saber administrativo, pois, muitas vezes, só a sua aplicação delimita seus aspectos positivos ou negativos. Assim, percebe-se uma história de ensaios, acertos, erros e novas promessas de abordagens.

$\mathrm{Na}$ perspectiva prática, há pressões para mais e melhores serviços e uma expectativa de solução imediata de problemas urgentes: $\mathrm{O}$ público espera da Administração Pública o melhor atendimento de suas demandas sociais, pelo uso eficiente de recursos e transparência dos atos.

De outra parte, o meio acadêmico, no anseio por oferecer diferentes e melhores alternativas, desenvolve propostas teóricas distintas, que, por vezes, rompem completamente com o passado ou representam práticas antigas com diferentes roupagens. A introdução de uma nova dimensão teórica revela sua potencialidade para solucionar questões específicas e contribuir para sua validade perante a comunidade, sem possibilidade de gerar verdades absolutas, tampouco de resolver problemas de maneira generalizada.

Por causa de um crescente dinamismo, novos problemas pressionam para novas soluções. Técnicas e processos de trabalho recém-introduzidos tornam-se rapidamente vulneráveis: sofrem os desgastes naturais de uma realidade mutante, mais complexa e demandante de maior eficiência. A recorrência dos temas, em face da experimentação, sedimenta o paradoxo da dúvida sobre relevância ou utilidade prática.

Resultados negativos e inesperados, bem como dificuldades práticas, conduzem a ciência a caminhos não trilhados com uma renovada esperança de contribuir para a solução de problemas.

\section{PRIMEIRAS PROPOSTAS PARA UMA CIÊNCIA DA ADMINISTRAÇÃO}

As ideias sobre uma Administração Pública eficiente avançaram com a Revolução Industrial e com o enfraquecimento dos poderes aristocratas e absolutistas. No século XVIII, por causa de uma incipiente burocracia pública, já havia, na 
Prússia, preocupações de gestão centradas no controle, nas finanças públicas e na comunicação das ordens públicas. Nesse mesmo período, a experiência prussiana levou não só à criação dos primeiros cursos de Administração Pública como também à proposta de uma nova ciência do cameralismo ou da Administração (AMATO, 1958).

No século XIX, problemas sociais, políticos e econômicos dominavam a Europa e, assim, acentuavam-se as inquietações sobre as práticas democráticas e a eficiência no setor público. Diferentes demandas e necessidades provocavam constantes reformas administrativas. Por serem ainda rudimentares, os conhecimentos sistematizados sobre a Administração pouco ajudavam na solução dos problemas.

Nessa mesma época, nações novas, como os Estados Unidos, buscavam nos modelos europeus inspiração para práticas democráticas. Presumiam-se as constituições e as leis como fundamentos lógicos e necessários para garantir a nova democracia. No entanto, problemas administrativos e ineficiência na prestação dos serviços revelavam a insuficiência da ordem jurídica. Constatou-se ser a criação de instituições políticas sólidas e responsáveis incapaz por si só para apoiar a ação efetiva do Estado.

Mesmo tendo sido a Europa pioneira em propor uma ciência da Administração pública, lá, de início, a ideia pouco progrediu, nem mesmo quanto da separação entre as atividades da política e da Administração. Para os europeus, a prevalência da dimensão constitucional legal sobre as ações administrativas seria uma garantia de eficiência e de eficácia na gestão pública. O direito público e, sobretudo, o direito administrativo, aliados à disciplina e a obediência às normas, forneceriam os padrões necessários e suficientes para uma boa gestão. Ademais, o sistema parlamentarista criara uma separação legal entre política e Administração. A ênfase no legalismo inibia ou tornava o debate, pelo menos no seu início, algo inócuo.

Vale notar que, na época da criação do Estado moderno, não se visualizava a Administração Pública como uma vasta prestadora de serviço, e sim como uma forma de ordenar o mundo democrático. Ao assumir dimensões de prestação de serviços, a eficiência da Administração Pública passou a ser um estágio importante para assegurar a democracia. Surgiam propostas para uma Administração independente da política e fundamentada em um campo de estudos e de conhecimentos próprios, como uma ciência. Apareciam os primeiros sinais de incentivo para o desenvolvimento dessa área do conhecimento.

Inspirado em Joseph Wharton, que proclamava a necessidade do ensino universitário em Administração para superar a gestão autocrática e baseada na família, em 1881, é criado o primeiro curso de graduação em Administração que sobreviveu às dificuldades e descrenças da época (SASS, 1983).

Os movimentos para uma nova ciência e o ensino da Administração parecem ter incentivado Woodrow Wilson, jurista e estudioso da Administração Pública que chegou à presidência dos EUA. Em 1887, Wilson fez uma proclamação sólida para o estudo e novas práticas da Administração pública: lembrava ser mais fácil fazer uma constituição e definir posturas democráticas do que aplicá-las. Admirador das práticas europeias e consciente da ineficiência crônica da Administração pública, Wilson preconizou a dicotomia - política e Administração - e a introdução do estilo privado na gestão pública. Pregava, ainda, a necessidade dos estudos sistematizados de Administração e a revisão geral da organização e dos métodos de trabalho no governo (WILSON, 1955).

Quando Wilson e Wharton propuseram uma nova ciência e uma nova prática administrativa, estavam conscientes de que a gestão pelos donos do poder, ou por leis, seria insuficiente para a gestão mais eficaz. O esforço para o ensino independente da Administração facilitava uma ciência da Administração Pública separada da política. Se separadas, as semelhanças com a gestão privada eram mais nítidas, e a gestão privada seria uma inspiração para a gestão pública. Ao se contemplar a Administração Pública fora da política, incluindo a neutralidade do servidor, facilmente se justificava a gestão pública semelhante à de uma empresa privada. A separação de política e Administração favorecia a visão gerencialista na Administração pública.

Posteriormente, no início do século XX, houve uma busca de princípios universais de Administração. No entanto, o avanço dos princípios administrativos foi concomitante às frustrações e decepções com a ineficiência da Administração pública. Tentativas de implantar neutralidade política e profissionalização da gestão pública enfrentavam imensos obstáculos políticos. Ademais, as práticas administrativas em vários países revelavam os limites da universalidade dos ainda incipientes princípios administrativos. 
Aos poucos, foi se desenvolvendo a crença de que a ciência da Administração Pública não progride independentemente de fortes laços políticos, do meio cultural, nem divorciada dos ditames de uma época. O estudo da Administração Pública deveria considerar peculiaridades e contexto, logo uma visão mais abrangente e holística. O modelo até então predominante era caracterizado pelo foco excessivo em mecanismos de controle, tendo como resultado a redução da eficiência, de mecanismos de transparência e da objetividade da Administração; daí a morosidade e o privilégio de interesses de grupos específicos.

Admitindo-se como impossíveis a neutralidade da gestão pública, seu distanciamento da política e a universalidade de princípios práticos, a melhor proposta seria comprometer os gestores públicos com valores essenciais. Esses valores serviram de base quase como uma ética universal de gestão, em que equidade, eficiência e eficácia condicionariam comportamentos administrativos, e não propostas práticas de gestão (FREDERICKSON, 1980; DENHARDT, 2012).

Surgiu, assim, nos anos 1970, o movimento da Nova Administração Pública - de duração efêmera pela: 1. dificuldade de operacionalizar os valores em termos práticos; 2 . aproximação maior com a política; 3. desconsideração inadvertida dos instrumentos práticos de gestão. A separação entre política e Administração continuou a ser o principal objetivo. A busca contínua de novos padrões de eficiência resultou no avanço da perspectiva gerencialista, resultando em novo movimento de grande impacto contemporâneo.

\section{Abordagem gerencial na Administração pública}

Desde o século XIX, propõe-se assemelhar a Administração Pública à empresa privada. Anunciada muitas vezes durante décadas - poucas vezes efetivada - essa ideia espalhou-se com uma nova e promissora modalidade de gestão pública nas últimas décadas do século XX. O New Public Management (NPM) apresentou-se com o objetivo primordial de fazer a Administração Pública operar como uma empresa privada e, assim, adquirir eficiência, reduzir custos e obter maior eficácia na prestação de serviços.

Como ideologia, o NPM recuperou ideais do liberalismo clássico, sobretudo a redução do escopo e do tamanho do Estado e a inserção do espírito e dos mecanismos de mercado no governo. Nesse sentido, a Administração Pública deveria apenas direcionar os serviços, e não executá-los diretamente. Havia uma preferência por terceirizar e contratar fora. Por meio de vários provedores privados, poder-se-iam usar os benefícios da competição entre eles, evitando monopólios e permitindo maior flexibilidade na gestão (OSBORNE e GAEBLER, 1995).

Ao pretender uma orientação mercadológica, propunha-se mais competição, descentralização e privatização, com maior poder para os gestores dos serviços. Ao governo, caberia executar funções que lhe seriam exclusivas e inapropriadas à execução ou ao controle por mecanismos de mercado (OSBORNE, 2010; DENHARDT, 2012; KETTL, 2000). Os servidores públicos desempenhariam as atividades-fim do Estado com maior eficiência, assumindo o papel de prestadores de serviço. Os cidadãos seriam vistos como clientes e usuários dos serviços públicos, em vez de meros recipientes da ação do Estado. O governo concentraria seus esforços nas suas atividades essenciais e exclusivas, direcionando e garantindo o suprimento das necessidades básicas (e direitos) da sociedade por meio de transferências para o setor privado e o terceiro setor. Por princípio, a Administração Pública desempenha algumas atividades melhor que as empresas e vice-versa (OSBORNE e GAEBLER, 1995).

O NPM viria a apresentar uma abordagem gerencial distinta, tendo focos no cliente, no gestor, no resultado e no desempenho. O foco no cliente viria a considerar o cidadão um cliente e incorporar singularidades das demandas individuais. O foco no gestor proporcionaria maior autonomia e flexibilidade para favorecer ajustes na linha de frente, fixar resultados, firmar contratos e controlar o desempenho organizacional; o intuito era de, possivelmente, criar uma cultura organizacional com valores empresariais. O foco no resultado traria, para a Administração pública, por meio do planejamento estratégico do tipo empresarial, as metas e os indicadores de desempenho. O foco no desempenho viria a substituir, em parte, as tradicionais avaliações por competições de mercado. Sugeriu-se que, pelo foco no produto, na eficiência e no resultado, as organizações públicas poderiam ter flexibilidade e autonomia para introduzir bônus pelo desempenho. Para avaliar, passariam a ser introduzidos orçamentos indicativos centrados em resultados que, como na empresa privada, facilitariam a flexibilidade da gestão. 
No sentido social, o NPM chegou a ser visto como um fator de legitimação política do estado social, que neutraliza a tentativa neoliberal de reduzir os serviços sociais e científicos prestados pelo Estado. O estado do bem-estar implicaria, dualmente, o grande aumento da organização estatal e da gestão mais eficiente e redução de custos, paralela à oferta de serviços de consumo coletivo (BRESSER PEREIRA, 2010).

As propostas do NPM avançaram rapidamente em época de nova ascensão das ideologias liberais, pois gastos e deficits públicos já assustavam governos. Promessas de reinvenção da Administração Pública eram bem-vindas pela população, pois trouxeram um novo otimismo na gestão pública por sucessivas idealizações de maior qualidade e eficiência. A crença em um mundo contemporâneo de mudanças rápidas e exigentes de novas soluções favorecia a proposição de inserção de práticas flexíveis de gestão privada no setor público.

As reformas associadas ao NPM encontraram entusiastas (HUGHES, 2003), críticos severos (FLYNN, 2012) e muitas análises sobre benefícios e consequências negativas (POLLITT e BOUCKAERT, 2004; PETERS, 2010; CHRISTENSEN e LAEGREID, 2007). Políticas públicas, estruturas, processos de trabalho e instrumentos gerenciais foram analisados, reacendendo os debates sobre os limites das teorias e práticas administrativas. Entre as críticas mais enfáticas ao NPM, vale mencionar:

\section{NPM não extinguiu controles tradicionais}

Mesmo nos países de maior avanço no NPM, as descentralizações, des- regulações e desburocratizações vieram sempre acompanhadas de novas centralizações e de novas regras, na maioria das vezes, aumentando o peso burocrático (KIRKPATRICK, ACKROYD, WALKER, 2005). No NPM, a tentativa de flexibilizar não extinguiu os controles tradicionais, mas também mostrou aumento da burocracia. Algumas reformas criaram mais regras burocráticas e mais níveis hierárquicos para controlar a suposta descentralização. Nos EUA, os tradicionais padrões de flexibilidade e pragmatismo na gestão, inspirados no estilo britânico, foram se reduzindo, e a burocratização alcançou um nível elevado (THE ECONOMIST, 2012).

Já há muito se destacava a ênfase no controle como a dificuldade básica para a eficiência da gestão pública (THOMPSON, 1967). Recentemente, ao analisar modelos organizacionais e reformas, com base no NPM, Secchi (2009) revelou características essenciais presentes nos novos modelos como típicas do tradicionalismo burocrático, continuando a ênfase no controle, não configurando, assim, modelos de ruptura. Por motivos políticos, o controle prolonga-se em áreas menos visíveis, sobretudo no sistema de implementação por meio da manipulação de instrumentos gerenciais (MOTTA, 1987). No Brasil, o planejamento, em vez de ser visto como um processo, é constantemente entendido como um produto técnico, uma forma de controle da economia e da sociedade (OLIVEIRA, 2006).

Também por motivos políticos de preservação da coalizão dos grupos no poder, a atividade de controle prevalece sobre qualquer outra dimensão gerencial. Poucos dirigentes se conformariam em se distanciar do conflito político para se restringir apenas a tarefas mais gerenciais.

\section{Práticas privadas resultaram em ganhos moderados para gestão pública}

Por serem sacudidas, todos os dias, por pressões de mercado e revoluções tecnológicas, as empresas privadas, para sobreviver, dependem da capacidade de agir com rapidez e introduzir o inusitado. A área pública, por sua vez, está sujeita a normas fixadas em leis e decretos, não fácil ou imediatamente alteradas: dependem de novos consensos políticos para introduzir novidades. A Administração Pública carrega dificuldades para resolver com rapidez problemas da comunidade: inserir a eficiência privada com a possibilidade de êxito imediato resultou, em grande parte, em mera ilusão.

Ademais, os incentivos à iniciativa e ao empreendedorismo encontraram obstáculos tanto na burocracia removida como nos novos controles. Ainda, a pressão por resultados levou a mais estresse, com desmotivação dos funcionários, pois foram praticamente inexistentes os bônus comuns à empresa privada.

As empresas privadas e as organizações públicas possuem características bastante distintas em termos de dinâmicas ou finalidades. Algumas dessas características podem ser camufladas nas formas institucionais, mas emergem rapidamente no cotidiano administrativo. Interferências políticas de instâncias superiores ocorrem a todo momento e não cessam nas opções do campo político/gerencial superior, mas desenvolvem-se continuamente e durante todas as etapas das ações administrativas. 
Portanto, na prática, é impossível conceder autonomia de decisão em meio a um controle político acentuado; o contexto da Administração Pública favorece mais a lealdade política e menos a lealdade organizacional - requisito para o êxito de novas práticas gerenciais. Os gestores públicos têm carreira e cargo mais vulneráveis à política e menos ao desempenho. Ademais, os controles políticos tornam as tarefas rotineiras não delegáveis, favorecendo a centralização e danificando todas as ideias de descentralização.

\section{NPM reativou descrença dos cidadãos}

De início, a receptividade do NPM foi bem elevada, mobilizando, inclusive, agências internacionais de desenvolvimento - grandes incentivadoras desse novo modelo. Normalmente, propostas de eficiência e de melhor desempenho tendem a ser muito populares, por causa da imagem tradicional de ineficiência nos serviços públicos. Lidar com a Administração Pública para obter algum serviço sempre resulta numa percepção de descaso para com os direitos de cidadania, principalmente nos países em desenvolvimento, onde ainda há forte demanda por mais e melhores serviços.

Para a maioria dos cidadãos, as novas práticas de gestão ligadas ao NPM mudaram muito pouco o acesso e a qualidade dos serviços públicos. O otimismo e o entusiasmo inicial com o NPM reduziram-se, não por decepção ideológica, mas pelo fracasso nos resultados e na qualidade do serviço público.

Mesmo quando mais empresariais, menos onerosas e mais eficientes, as administrações públicas não se tornaram mais simpáticas aos cidadãos: as convergências de lógicas econômicas, do mercado, do Estado e da sociedade civil ressaltaram o lado econômico mercadológico e resultaram pouco favoráveis ao cidadão (KISSLER e HEIDEMANN, 2006).

\section{NPM carrega valores culturais dos países de criação}

Os relatos de maior sucesso com as práticas do NPM são oriundos das nações já dominadas pelo pragmatismo gerencial e pela baixa imposição de normas burocráticas e maior democracia na gestão (CHRISTENSEN e LAEGREID, 2007; POLLITT, 1990). Possivelmente por já terem, comparativamente, maior flexibilidade burocrática, menos regras formais e rígidas, menos degraus hierárquicos e objetivos bem definidos, aceitavam e implantavam mais facilmente as propostas do NPM. Nessas sociedades, mudanças administrativas carregam valores e crenças do próprio contexto cultural, e, assim, são relativamente mais simples: causam menos transtornos e, na maioria das vezes, alcançam os resultados esperados.

O mesmo não acontece com países de extensa burocracia, com acentuado legalismo e formalismo e forte autoridade hierárquica (BORINS, 2002; KICKERT, 1997; SCHEDLER e PROELLER, 2002). Ademais, nas sociedades em transição, a coexistência de valores modernos e tradicionais, como as fortes tradições patrimonialistas e as reformas modernizantes, deixa resultados e apoios duvidosos, gerando receios e acentuando a descrença das pessoas e a resistência às mudanças (JREISAT, 2012; MOTTA, 1987).

\section{Foco no gestor mostrou-se demasiadamente simplista}

Os relatos e as imagens sobre a ineficiência administrativa espalham a crença de dirigentes públicos como incompetentes por falta de bom senso e por desconhecimento de princípios elementares de gerência moderna.

São demasiadamente simplistas para a gestão pública: desconsideraram as dimensões políticas e as condições de trabalho nas organizações públicas. O gestor público está inserido em uma luta de poder capaz de deixar seu cargo politicamente vulnerável em cada decisão tomada. Resolver conflitos torna-se mais importante e toma mais tempo que buscar resultados. Entre suas tarefas principais, inclui-se a busca constante de novos consensos em meio a pressões, conflitos, alianças e agudas limitações de recursos. No gestor, refletem-se as próprias condições de ambiguidade, conflito e desigualdade na distribuição dos recursos de poder. Propostas de mudanças sempre enfrentam as coalizões de poder: diagnósticos negativos servem para introduzir novos métodos, tanto para melhorar o desempenho como para assegurar interesses de poder já conquistados. O resultado dessas práticas são danos de longo prazo nos serviços, no desempenho e na cultura organizacional (DIEFENBACH, 2009).

$\mathrm{Na}$ verdade, é insuficiente oferecer treinamento e autonomia para tornar os dirigentes mais eficientes e eficazes. Por maior que seja a autonomia concedida a uma organização pública, a maioria de seus dirigentes possui apenas um mínimo de poder sobre os objetivos dos órgãos que dirigem. Os objetivos e as formas de atuação 
são negociados com os diversos grupos de poder, envolvendo, inclusive, os termos de seu próprio trabalho (MOTTA, 1987).

Após os insucessos de propostas trazidas pelo NPM, alguns dilemas da Administração Pública ainda precisam ser enfrentados. Entre eles, estão a integração das dimensões políticas e administrativas no mesmo espaço de decisão e ações públicas e a insistência nas perspectivas e práticas descentralizadoras da gestão privada na Administração pública.

\section{Dilemas do pós-NPM}

Integrar dimensões políticas e administrativas no mesmo espaço de decisão e ações públicas é um dilema que recupera, para os estudiosos e praticantes, as dificuldades relacionadas não só à formação de uma ciência da Administração Pública como também a como ultrapassar problemas de ineficiência da gestão pública. A legítima função política é fazer funcionar as organizações públicas, segundo diretrizes, democraticamente conquistada em eleições, e não se imiscuir no seu funcionamento. Impor diretrizes políticas no expediente das organizações públicas é o preço que se paga para se ter democracia fora dele (WALDO, 1948).

A gestão pública carrega princípios e práticas centrais de ordem, uniformidade e equidade, além de objetivos múltiplos para garantir consenso e apoio político. A Administração Pública é pública, e, portanto, dissociá-la da política é praticamente impossível e democraticamente indesejável. Ademais, o poder político é sempre superior ao administrativo, sendo impossível ou inocente tentar contorná-lo (SHARKANSKY, 1979). A organiza- ção pública aparece, ilusoriamente, como um instrumento capaz de contornar a política; procura-se resolver problemas de conflitos típicos do pluralismo do sistema de grupos políticos por meio de esquemas administrativos (MOTTA, 1987). Qualquer instrumento gerencial inspirado na área privada esbarra nos limites políticos.

Possibilidades de convívio mais adequado e eficiente exigiriam maior profissionalização da política antes de se pensar em profissionalizar a Administração. As práticas privadas são, por definição, fragmentadas conforme objetivos, limitadas por busca de lucros e descentralizadas para se aproximar de clientes e enfrentar competidores.

A introdução de dimensões privadas na gestão pública exige grande fragmentação e uma variedade muito ampla de formas organizacionais. Como há pelejas políticas, a fragmentação induz ao aumento de formas de controle. Com frequência, sistemas de controle visam menos à defesa de ambiguidades e incertezas do ambiente socioeconômico e mais à proteção contra adversários políticos. Fazer as ideias de um grupo prevalecerem sobre as de outros acaba por dominar todas as formas de gestão, desde o planejamento à avaliação de desempenho.

A contemporaneidade administrativa reforça a necessidade de flexibilidade e da mentalidade da mudança cotidiana, dos resultados e do desempenho eficiente e eficaz das organizações públicas. Mas práticas administrativas são produto direto da natureza da interligação entre a Administração e a política. Só se pode obter uma Administração mais eficiente e eficaz com uma interação com o sistema político, mais ligado às expectativas da sociedade, mais congruente com valores e menos para fins preferenciais ou tecnocráticos.

Como a gestão privada é, também, mais rápida na produção de novas ideias gerenciais, ela continua ser uma referência atrativa e promissora para inovar o serviço público. Os movimentos pós- NPM continuam a ter os modelos de gestão privada como base de reformas. O NPM não morreu (VERHOEST e LAEGREID, 2010), mas passa por transformações e ajustes, resultando em maior complexidade e turbulência no ambiente das organizações públicas, pela tentativa de maior consideração do contexto político institucional.

A nova centralização surge como resposta à necessidade de melhor resolver crises econômicas e como tentativa de recompor a integração de políticas públicas, fruto da excessiva descentralização e fragmentação imposta pelo NPM. Há, também, a justificativa de retomar parcelas do poder político.

Enquanto a centralização está no cerne da Administração pública, a descentralização atrai atenção em termos de participação dos cidadãos (WAGENAAR, 2004). A maior descentralização e autonomia do gestor público pretende deixá-la numa relação mais poderosa e próxima às comunidades. $\mathrm{Na}$ verdade, cria-se a possibilidade de retirar parcelas de poder e de influência da classe política junto aos cidadãos.

\section{Oportunidade de transcender o NPM e rever as concepções de gestão}

Como transcender o NPM, se persiste a crença na inserção de mais práticas de gestão empresarial? 
Discursos oficiais sobre mudanças na gestão pública continuam a insistir no ideal gerencialista. Como qualquer outra ideologia, é uma concepção normativa, idealizada, e aparece como positiva e natural. Entretanto, a pressão da sociedade por novos valores e padrões de eficiência propostos no pós-NPM procura aproveitar as expectativas da comunidade para envolvê-la direta e indiretamente na gestão.

Atualmente, há uma grande decepção com a representação política, desfavorecendo o seu maior papel na solução de problemas. Correndo o risco de enfraquecer instituições políticas de representação, por excesso de democracia direta nas bases, reativa-se um novo tipo de competências e de interligação com o sistema político, por meio do poder comunitário. Pretende-se, com isso, favorecer a democracia com o uso de recursos comunitários para maior eficiência da gestão pública e a minimização de ideias de voltar a expandir as funções do Estado.

Abrucio (2007) sugere que a Administração Pública eficiente e efetiva emerge como fruto da cobrança e do controle pela sociedade. Denhardt e Denhardt (2007) recomendam um novo serviço público, baseado menos no direcionamento político e mais na prestação do serviço. Muitos indicam a forma cooperada como base da eficiência e da democracia administrativa: aumentar cooperação entre órgãos e entidades externas e considerar com mais ênfase as sugestões comunitárias (BINGHAM e O'LEARY, 2008; O'LEARY e BINGHAM, 2009; WILLIAMS, 2012). Com a aproximação dos diversos agentes públicos e da comunidade, e a inserção da forma cooperada em toda a cadeia produtiva, o pa- pel e a proatividade do governo tendem a se reduzir (SANTOS e PINHEIRO, 2011).

Por isso, as propostas modernas de transcendência levam para a localização do controle e participação comunitária, e não para a formalização de mais controles centrais. Parecem tentar resolver primeiro o problema da democracia e, por meio desta, ter mais e melhores serviços. Ademais, o excesso de propostas essencialmente gerencialistas na última década parece ter desconsiderado, inadvertidamente, dimensões democráticas do serviço público. Uma opção seria encontrar novas formas de envolver a sociedade civil e mercados no governo e enfraquecer os aspectos políticos de governar (PETERS, 2010), buscando, obviamente, o equilíbrio na aplicação dos interesses de todos os envolvidos.

O pós-NPM parece ter melhor consciência sobre os limites da inserção de mecanismos privados na gestão pública. A inviabilização fica demonstrada pela tentativa de adoção na totalidade. Algumas concepções e instrumentos de gestão praticados na empresa privada como a perspectiva sobre a qualidade da despesa e o foco no cliente - podem dar mais consistência e produtividade às ações públicas, mas também danificar valores fundamentais do serviço público.

Em contrapartida, valores clássicos da Administração Pública como a equidade e igualdade - podem ser usados para justificar ineficiências por simples contradição com o espírito privado. A equidade possui uma dupla conotação: a de distribuição uniforme de custos e benefícios entre todos os cidadãos e a de distribuição não uniforme, privilegiando os mais necessitados
(OLLAIK e MEDEIROS, 2011). A busca da equidade, por base distributiva, será prioritária entre os países emergentes, com a recuperação da classe média e os avanços da distribuição da riqueza. Há, ainda, controvérsias importantes sobre as possibilidades do NPM como causa ou resposta à equidade social e a concomitância da eficiência e equidade (TAYLOR, 2002; HARROW, 2002). Assim, a forma sobre como a Administração Pública adapta-se ao processo de governança de uma sociedade mais democrática e mais consciente de seu poder de influência deverá direcionar o estilo de gestão a ser praticado.

Por fim, a recuperação de valor dos conhecimentos administrativos reflete a necessidade de contraposição às práticas políticas. Cabe conciliar lições aprendidas no meio privado com o meio público, respeitando, porém, características inerentes à Administração pública. Nessa preservação das dimensões públicas como reação ao NPM, aparecem novas perspectivas sobre a qualidade do governo. As ideias sobre nova governança pública trazem propostas de maior formalidade no estilo weberiano e uma justificativa mais acentuada sobre eficiência (CHRISTENSEN e LAEGREID, 2011). Na verdade, essas propostas implicam novo papel do Estado na sociedade, talvez mais direcionador e fiscalizador, com repercussões significativas sobre a gestão pública. Na época atual, as justificativas são, ainda, de medidas temporárias e pontuais, baseadas na necessidade de enfrentar crises econômicas. Porém, permanece a expectativa de essas medidas possuírem o vigor de ultrapassar as crises e configurar uma nova reconstrução da Administração pública 


\section{CONSIDERAÇÕES FINAIS}

A globalização e a complexidade do mundo contemporâneo têm acentuado as dificuldades e mesmo a incapacidade dos governos nacionais de resolverem, por si sós, problemas de progresso. Maior interdependência entre nações afeta funções e interligações de órgãos da Administração pública, com maior variedade de instituições, nacionais, estrangeiras e empresas privadas. Órgãos públicos se veem diante de um ambiente de risco e de competitividade na complexidade da cadeia de valores que interligam os sistemas produtivos nacionais e internacionais.

Anunciada como um universo de oportunidades, a globalização contém riscos, e, nos momentos de maior tensão e competição, a Administração Pública é normalmente chamada a intervir e participar. A complexidade aliada à interdependência faz com que pequenos problemas, ocorridos mesmo em nações muito distantes, tenham grandes impactos, exigindo ações imediatas dos órgãos públicos.

Impossível planejar e agir, em qualquer área da Administração, sem a visão planetária - ou holística. Essa visão impõe a consciência sobre um maior número de fatores e perspectiva da Administração Pública como associada a toda uma cadeia produtiva mundial, gerenciada diretamente por empresas privadas, interligada a governos de diversas nações. Atribui, ainda, à Administração Pública um novo papel colaborativo, de incentivo, de regulação e de controle, para proteger não só a produção de bens e serviços mas o próprio interesse nacional. Essas novas condições não só põem em xeque a validade das conquistas e novidades mais recentes como também aguçam a tradição de buscar formas de gestão mais aplicáveis e relevantes. São tantas as decepções e as necessidades manifestas da Administração Pública que parece ainda um caminho pouco trilhado, apesar das recentes inovações.

\section{REFERÊNCIAS}

ABRUCIO, F. L. Trajetória recente da gestão pública brasileira: um balanço crítico e a renovação da agenda de reformas. Revista de Administração Pública, Edição Especial Comemorativa, p. 67-86, 2007.

AMATO, P. M. Introdução à Administração pública. Rio de Janeiro: Fundação Getulio Vargas, 1958.

BINGHAM, L; O'LEARY, R. Big ideas in collaborative public management. New York: ME Sharpe, 2008.

BORINS, S. New public management: North American style. In: McLAUGHLIN, K; OSBORNE, S; FERLIE, E. (Coords). The new public management current trends and future prospects. Londres: Routledge, 2002.

BRESSER-PEREIRA, L. C. Democracia, estado social e reforma gerencial. RAE-Revista de Administração de Empresas, v. 50, n. 1, p. 112-116, 2010.

CHRISTENSEN, T; LAEGREID, P. The Ashgate Research Companion to new public management. Farham: Ashgate, 2011.

CHRISTENSEN, T; LAEGREID, P. Transcending new public management. Hampshire: Ashgate, 2007.
DENHARDT, J; DENHARDT, R. The new public service: serving not steering. New York: M.E. Sharpe, 2007.

DENHARDT, R. B. Teoria geral da Administração pública. São Paulo: Cengage, 2012.

DIEFENBACH, T. New public management in public sector organizations: the dark side of managerialistic "enlightenment". Public Administration, v. 87, n. 4, p. 892-909, 2009.

FLYNN, N. Public sector management. Londres: Sage, 2012.

FREDERICKSON, H. G. New public administration. Alabama: University of Alabama, 1980.

HARROW, J. The new public management and social justice: just efficiency or equity as well? In: MCLAUGHLIN, K; OSBORNE, S; FERLIE, E. (Coords). The new public management current trends and future prospects. Londres: Routledge, 2002.

HUGHES, O. E. Public management and administration. Basingstoke: Palgrave Macmillan, 2003.

JREISAT, J. Globalism and comparative public administration. Boca Raton: CRC, 2012.

KETTLE, D. F. The global public management revolution. Washington DC: The Brookings Institution, 2000.

KICKERT, W. J. M. Public governance in The Netherlands: an alternative to Anglo American managerialism. Public Administration, v. 75, n. 4, p. 731-752, 1997.

KIRKPATRICK, I; ACKROYD, S; WALKER, R. The new managerialism and public service professions: change 
in health, social services and housing. New York: Palgrave MacMillan, 2005.

KISSLER, L; HEIDEMANN, F. G. Governança pública: novo modelo regulatório para as relações entre Estado, mercado e sociedade? Revista de Administração Pública, v. 40, n. 3, p. 479-499, 2006.

MOTTA, P. R. Modernização administrativa: propostas alternativas para $\mathrm{O}$ Estado latino-americano. Revista de Administração Pública, v. 21, n. 4, p. 31-61, 1987.

O'LEARY, R; BINGHAM, L. B. (Coords). The collaborative public manager. new ideas for the twenty-first century. Washington DC: Georgetown University, 2009.

Oliveira, J. A. P. de. Desafios do planejamento em políticas públicas: diferentes visões e práticas. Revista de Administração Pública, v. 40, n. 1, p. 273-288, 2006.

OLLAIK, L. G; MEDEIROS, J. J. Instrumentos governamentais: reflexões para uma agenda de pesquisas sobre implementação de políticas públicas no Brasil. Revista de Administração Pública, v. 45, n. 6, p. 1943-1967, 2011.

OSBORNE, S. The new public governance? Londres: Routledge, 2010.

OSBORNE, D; GAEBLER, T. Reinventando o governo. 6. ed. Brasília: $\mathrm{MH}$ Comunicação, 1995.

PETERS, B. G. The new public governance? Emerging perspectives on the theory and practice of public governance. Londres: Routledge, 2010.

POLLITT, C; BOUCKAERT, G. Public management reform: a comparative analysis. Oxford: Oxford University, 2004.

POLLITT, C. Managerialism and the public services: the Anglo-Saxon experience. Oxford: Basil Blackwell, 1990.

SANTOS, M. S. dos; PINHEIRO, I. A. Governo: um aliado nem sempre lembrado pelas empresas na hora de desenvolver as atividades de P\&D. Revista de Administração Pública, v. 45, n. 5, p. 1463-1483, 2011.

SASS, S. A. Pragmatic imagination: a history of the Wharton School, 18811981. Philadelphia: University of Pennsylvania, 1983.

SCHEDLER, K; PROELLER, I. The new public management: a perspective from mainland Europe. In: McLAUGHLIN, K; OSBORNE, S; FERLIE, E. (Coords). The new public management current trends and future prospects. Londres: Routledge, 2002.

SECCHI, L. Modelos organizacionais e reformas da Administração pública. Revista de Administração Pública, v. 43, n. 2, p. 347-369, 2009.

SHARKANSKY. I. Wither the state? Politics and public enterprise in three countries. Chathan, New Jersey: Chatham House, 1979.

TAYLOR, M. The new public management and social exclusion: cause or response. In: MCLAUGHLIN, K; OSBORNE, S; FERLIE, E. (Coords). The new public management current trends and future prospects. Londres: Routledge, 2002.

THE ECONOMIST, 2012. Over regulated America.

THOMPSON, V. A moderna organização. Rio de Janeiro: Freitas Bastos, 1967.
VERHOEST, K; LAEGREID, P. Organizing public sector agencies: challenges and reflections. In: LAEGREID, P; VERHOEST, K. (Coords). Governance of public sector organizations: proliferation, autonomy and performance. Hampshire: Palgrave MacMullan, 2010.

WAGENAAR, H. Knowing" the Rules: Administrative Work as Practice. Public Administration Review, v.64, n.6, p. 643-656, 2004.

WALDO, D. The administrative state. New York: Ronald, 1948.

WILLIAMS, P. Collaboration in public policy and practice. Bristol: The Policy, 2012.

WILSON, W. O estudo da Administração. Rio de Janeiro: FGV, 1955. 